\title{
Users' perspectives on non-clinical quality of care in public and private primary healthcare in Albania
}

\section{CURRENT STATUS: UNDER REVIEW}

BMC Family Practice $\triangle$ BMC Series

Jonila Gabrani

Schweizerisches Tropen- und Public Health-Institut

ฯ jonila11@yahoo.comCorresponding Author

Christian Schindler

Schweizerisches Tropen- und Public Health-Institut

Kaspar Wyss

Schweizerisches Tropen- und Public Health-Institut

\section{DOI:}

$10.21203 / \mathrm{rs} .2 .24536 / \mathrm{v} 1$

\section{SUBJECT AREAS}

General Practice

\section{KEYWORDS}

primary care, quality of care, communication, dignity, private provider, autonomy, non-communicable disease, Albania, South-East Europe 
Abstract

Background: Aiming to tackle the rise of non-communicable diseases and an ageing population, Albania is engaged in boosting primary healthcare services and quality of care. The patients' perspectives on their experience with public and private providers are, however, missing, although their viewpoints are critical while shaping the developing services. Consequently, we analyse perceptions of users of PHC services as it relates to non-clinical quality of care and the association to sociodemographic characteristics of patients and the type of provider.

Methods: A facility-based survey was conducted in 2018 using the World Health Organization responsiveness questionnaire which is based on a 4-point scale along eight non-clinical domains of quality of care. The data of 954 patients were analysed through descriptive statistics and linear mixed regression models.

Results: Similar mean values were reported on total scale of the quality of care for private and public providers, also after sociodemographic adjustments. The highest mean scores was reported for the domain 'communication' (3.75) followed by 'dignity' (3.65), while the lowest mean scores were given for 'choice' (2.89) and 'prompt attention' (3.00). Urban governmental PHC services were rated significantly better than private outpatient clinics in 'coordination of care' (2.90 vs $2.12, p<0.001)$. In contrast, private outpatient clinics were rated significantly higher than urban PHC clinics in 'confidentiality' (3.77 vs 3.38, $p=0.04$ ) and 'quality of basic amenities' (3.70 vs 3.02, $p<0.001$ ). For the other domains, no statistically significant differences were observed. 'Autonomy' was reported as least important attribute of quality. Enrolment in health insurance was a predictor of higher quality ratings (coefficient $=0.06, p=0.02$ )

Conclusion: While the perception of non-clinical care quality was found to be high and similar for public and private providers, promptness and coordination of care require attention to meet patient's expectations on good quality of care. There is a need to shift from a 'paternalistic' model to a 'comanaging the illness', raising awareness on autonomy.

Full Text

Due to technical limitations, full-text HTML conversion of this manuscript could not be completed. 
However, the manuscript can be downloaded and accessed as a PDF.

\section{Figures}

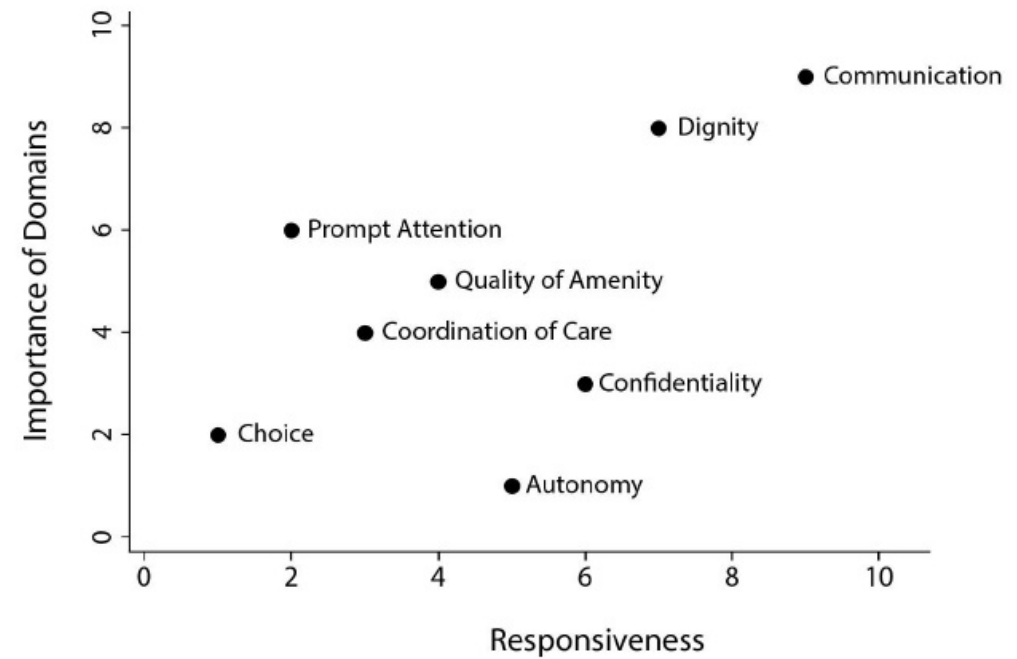

† Importance of the domains were calculated based on the patients' individual ranking and were then crossed with the respective domains' mean values (responsiveness).

Figure 1

Importance and associated responsiveness of attributes of non-clinical quality of care $\dagger$ 